\title{
Evaluation of the quality of life of patients with oral cancer in Brazil
}

\section{Avaliação da qualidade de vida de pacientes com câncer bucal no Brasil}

\author{
Fabiana Paula de Andrade* \\ José Leopoldo Ferreira Antunes** \\ Marcelo Doria Durazzo***
}

\begin{abstract}
This study performed a field trial of a Portuguese version of the University of Washington quality of life questionnaire (UW-QOL, $3^{\text {rd }}$ version), aiming at appraising its ability to identify different patterns of health-related quality of life of patients with oral cancer in Brazil. Patients $(N=100)$ were interviewed as they were undergoing treatment for oral squamous cell carcinoma at a large Brazilian hospital ("Hospital das Clínicas", School of Medicine, University of São Paulo). The results were compared based on categories of socio-demographic and clinical characteristics of the patients. At a one-year follow-up, 20 patients had died, and 24 were considered dropouts. The remaining patients accounted for the longitudinal assessment of modifications in the self report of quality of life. Patients with larger tumours and neoplasms in the posterior part of the mouth presented significantly $(\mathrm{p}<0.05)$ poorer indications of quality of life. Chewing was the poorest rated domain (35.0/100.0), and presented the highest proportion of complaints both at the baseline and at the follow-up assessments. The questionnaire allowed the identification of important contrasts (while comparing clinical characteristics) and similarities (while comparing socio-demographic status) among subsets of respondents, and it can contribute to reduce the impact of treatments and improve subsequent patient management.
\end{abstract}

DESCRIPTORS: Quality of life; Mouth neoplasms; Chewing; Questionnaires; Brazil.

RESUMO: O presente estudo realizou teste de campo para uma versão em Português do questionário de qualidade de vida da Universidade de Washington (UW-QOL, $3^{a}$ versão), com o intuito de avaliar sua capacidade em descrever padrões diferenciais de qualidade de vida de pacientes com câncer de boca no contexto brasileiro. Foram entrevistados 100 pacientes com carcinoma epidermóide oral no Hospital das Clínicas da Faculdade de Medicina da Universidade de São Paulo. Os resultados foram comparados por características sócio-demográficas e clínicas dos pacientes. Após um ano, 20 pacientes haviam falecido e 24 não foram localizados. A re-entrevista dos demais permitiu o acompanhamento longitudinal de modificações na auto-avaliação de qualidade de vida. Pacientes com tumores maiores e neoplasia na porção posterior da boca apresentaram indicadores de pior qualidade de vida ( $\mathrm{p}<0.05)$. Mastigação foi o item com pior avaliação $(35,0 / 100,0)$ e maior proporção de queixas, tanto na avaliação inicial como no seguimento longitudinal. O questionário permitiu identificar relevantes contrastes (na comparação de características clínicas) e similaridades (na comparação de características sócio-demográficas) entre os grupos de respondentes. Seu uso regular no hospital pode contribuir para reduzir o impacto das aplicações terapêuticas e aprimorar a gestão dos tratamentos.

DESCRITORES: Qualidade de vida; Neoplasias bucais; Mastigação; Questionários; Brasil.

\section{INTRODUCTION}

"Quality of life" - QOL is a construct increasingly used in the assessment of health status and the impact of therapeutic applications in patients with different diseases. In 1994, a panel of researchers of the World Health Organization proposed a unifying and trans-cultural definition of QOL as "the individual's perception of his or her position in life, within the cultural context and value system he or she lives in, and in relation to his or her goals, expectations, parameters and social relations. It is a broad ranging concept affected in a complex way by the person's physical health, psychological state, level of independence, social relationships and their relationship to salient features of the environment". ${ }^{11}$ The WHO-QOL group considered early attempts at QOL assess-

* Graduate (MSc) Student; **Associate Professor, Department of Social Dentistry - School of Dentistry, University of São Paulo. *** Physician, Department of Head and Neck Surgery, School of Medicine, University of São Paulo. 
Andrade FP, Antunes JLF, Durazzo MD. Evaluation of the quality of life of patients with oral cancer in Brazil. Braz Oral Res 2006;20(4):290-6.

ments that went beyond physical health status as not comprehensive enough and lacking reliability. Afterwards, newly developed questionnaires aimed at a wider assessment of potentially independent QOL domains, and several studies appraised the reliability and validity of these tools. ${ }^{12}$

For patients with oral cancer, the self-oriented QOL evaluation is a useful adjunct to the more traditional measures assessing the effectiveness of therapies. Despite recent advances in diagnosis and treatment, oral cancer remains associated with disfigurement and dysfunctions that affect essential domains of life. The importance of assessing the self-reported evaluation of functional status and well-being of patients with cancer has been well documented in the literature. ${ }^{10}$

The World Health Organization and the International Agency for Research on Cancer $^{9}$ (2003) acknowledged oral cancer as the most common neoplasm of the head and neck, with nearly 390,000 new cases per year. Franceschi et al. ${ }^{2}$ (2000) classified the Brazilian information on oral and pharyngeal cancer incidence amongst the highest worldwide. Wünsch-Filho ${ }^{14}$ (2002) reported a higher incidence of cancer in the mouth and pharynx for São Paulo than for the overall Brazilian context. The incidence of oral and oropharyngeal cancer - referring to the $\mathrm{C} 00-\mathrm{C} 10$ codes of the International Classification of Diseases, $10^{\text {th }}$ revision - corresponded to $5.70 \%$ and $2.26 \%$ of all cancers (excluded those affecting the skin), respectively for males and females, in the city of São Paulo from 1997 to $1999 .^{5}$

These considerations account for the importance of QOL assessments for patients with oral cancer in the Brazilian context. The present study comprises a field trial for the Portuguese version of a QOL questionnaire specifically addressed for patients with cancer of the head and neck, and aims at appraising its effectiveness in identifying covariates for several QOL items. We also aimed at fostering further studies on QOL in cross-cultural contexts, by appraising the questionnaire's applicability for patients with oral squamous cell carcinoma in a large hospital setting.

\section{METHODS}

We assessed the quality of life of oral cancer patients undergoing treatment in the head and neck surgery centre of a major Brazilian hospital ("Hospital das Clinicas", School of Medicine, University of São Paulo) from August 2002 to January 2003. The study gathered information for 100 patients with squamous cell carcinoma in the following sites: Cheek mucosa (1), vestibule of the mouth (3), floor of the mouth (23), gum (5), lips (6), palate (14), retromolar area (12), tongue (32), tonsil (1) and oropharynx (3). Most patients (57) had already undergone surgery, and 40 of them had begun postoperative radiotherapy. Eleven patients with T4 tumours would not benefit from surgery, and had already been submitted to radio- and chemotherapy when interviewed; and 32 patients were preparing for surgery. As to tumour size, the sample comprised 15 patients classified as T1, 24 classified as T2, 14 classified as T3, and 47 classified as T4.

The form submitted to participants was a Portuguese version of the University of Washington Quality of Life (UW-QOL, version 3) questionnaire (downloaded at http://depts.washington.edu/ soar/projects/dxcat/hnca/qol_uw.htm), which was specifically developed for the QOL assessment of patients with cancer of the head and neck. It comprises ten specific questions addressing relevant dimensions for the QOL assessment of patients with oral and oropharyngeal cancer: pain, appearance, activity, recreation, swallowing, chewing, speech, shoulder, taste and saliva. A Likert-scale score allowed assigning ratings from 0 to 100 for each possible answer, with higher figures indicating improved QOL status. ${ }^{13}$

Direct observation of the hospital registers identified the socio-demographic (age, gender, income, and educational attainment) and clinical characteristics (site of the neoplasm, TNM classification, type and stage of treatment) of the patients. Income was measured in terms of the Brazilian minimum wage - a unit of measurement roughly corresponding to US\$ 85 -, and educational attainment differentiated patients with no schooling or fundamental education from those that concluded high school or college. TNM classification allowed the comparison between patients presenting T1 and T2 tumours and those presenting T3 and T4. According to the site of the neoplasm, tumours were classified as located in the anterior part (lips, vestibule and floor of the mouth, cheek mucosa, hard palate, gum and anterior two-thirds of the tongue) or posterior part (base of the tongue, soft palate, retromolar area, tonsil and oropharynx) of the mouth and oropharynx.

These categories were used to assess ratios comparing answers for general questions and ratings for QOL specific domains. Comparative analyses of proportions used one-sided $\mathrm{p}$-values as calculated by Fisher's exact test; comparative analyses of scores 
Andrade FP, Antunes JLF, Durazzo MD. Evaluation of the quality of life of patients with oral cancer in Brazil. Braz Oral Res 2006;20(4):290-6.

assigned to specific QOL items used Student's $t$ test for independent samples. Statistical analysis was performed with the SPSS 8.0 software (1997).

At the one-year follow-up, 20 patients had died and 24 patients could not be contacted. The remaining 56 patients answered again the UW-QOL questionnaire, accounting for the longitudinal appraisal of QOL, which used the proportion of overall agreement for general questions, and Cronbach's alpha for the domain-specific ratings.

\section{RESULTS}

More than half of the patients with oral cancer reported worse QOL than in the month preceding the diagnosis, and a non-negligible proportion of them declared poor health-related and overall QOL during the week preceding the survey (Table 1). A significantly higher proportion of patients with T3 and T4 tumours and with cancer in the posterior part of the oral cavity stated that their QOL worsened after diagnosis and treatment. Patients aged less than 60 years old complained to a lesser extent about their overall QOL during the preceding week.

Table 2 indicates that tumour size, location, surgery and radiotherapy were the most important conditions modifying the overall rating of healthrelated QOL. Table 2 also displays the most important conditions associated with reduced ratings for each specific item. Males ranked lower ratings than females for chewing, saliva, swallowing and taste.
Patients with T3 and T4 tumours ranked lower ratings for chewing, swallowing, saliva, pain, taste and speech. Patients submitted to radiotherapy presented significantly lower ratings for almost all specific items. Surgery was also associated with poorer ratings for specific domains: saliva, shoulder and appearance. However, patients preparing or not suitable for surgery ranked a significantly lower rating for pain than those already submitted to surgery. Income and age group did not associate with any specific rating.

Chewing was by far the most frequent complaint, followed by difficulties in swallowing, pain and reduced saliva flow (Table 3 ). Tumour size was the major condition associated with increased complaints of chewing and swallowing difficulties. Pain was homogeneously distributed as a frequent complaint in different categories of age, gender, income, educational attainment, location, T stage and application for radiotherapy; however, a lower proportion of patients already submitted to surgery indicated pain as one of the three most important complaints. Age, schooling level, radiotherapy and surgical status were associated with an increased proportion of complaints regarding dry mouth (Table 3).

Although half of the 56 patients participating in the longitudinal assessment appraised their health-related QOL at the baseline as worse than during the month before diagnosis, at the one-year follow-up, this proportion was reduced to one third. With borderline statistical significance (Fisher's

TABLE 1 - Baseline assessment of quality of life (QOL) general questions: ratios of proportions of answers among subsets of patients with oral cancer in São Paulo, 2002.

\begin{tabular}{|c|c|c|c|c|}
\hline Condition & Compared groups & $\begin{array}{l}\text { Relating worse } \\
\text { QOL compared to } \\
\text { the month before } \\
\text { the diagnosis }\end{array}$ & $\begin{array}{l}\text { Relating poor } \\
\text { health-related } \\
\text { QOL during the } \\
\text { preceding week }\end{array}$ & $\begin{array}{l}\text { Relating poor } \\
\text { overall QOL } \\
\text { during the } \\
\text { preceding week }\end{array}$ \\
\hline Age & $\geq 60 \operatorname{yrs}(\mathrm{n}=65) /<60$ yrs $(\mathrm{n}=35)$ & 1.22 & 1.71 & $2.67 * * *$ \\
\hline Gender & Females $(\mathrm{n}=29) /$ Males $(\mathrm{n}=71)$ & 0.96 & 1.20 & 1.91 \\
\hline Income & $\begin{array}{l}\leq 1 \text { Brazilian } \mathrm{MW}^{*}(\mathrm{n}=36) / \\
>1 \text { Brazilian } \mathrm{MW}^{*}(\mathrm{n}=64)\end{array}$ & 1.16 & 1.10 & 1.31 \\
\hline $\begin{array}{l}\text { Schooling } \\
\text { level }\end{array}$ & $\begin{array}{l}\text { Elementary school or less }(n=78) / \\
\text { High school or more }(n=22)\end{array}$ & 0.72 & 1.50 & 1.46 \\
\hline Location & Posterior $(n=33) /$ Anterior $(n=67)$ & $2.42^{* *}$ & 1.33 & 0.60 \\
\hline T stage & $\mathrm{T} 3$ and T4 $(\mathrm{n}=61) / \mathrm{T} 1$ and T2 $(\mathrm{n}=39)$ & $1.37^{* * *}$ & 0.73 & 1.23 \\
\hline Radiotherapy & Yes $(n=51) /$ No $(n=49)$ & 1.08 & 0.75 & 1.80 \\
\hline Surgery & Yes $(n=57) /$ No $(n=43)$ & 1.06 & 0.83 & 1.33 \\
\hline \multicolumn{2}{|c|}{ Overall proportion $(n=100)$} & $53 \%$ & $21 \%$ & $14 \%$ \\
\hline
\end{tabular}

*Brazilian MW = Brazilian minimum wage ( US\$ 85). ${ }^{* *}$ Compared groups differ significantly at the p $<0.05$ level. ${ }^{* * *}$ Compared groups differ significantly at the $\mathrm{p}<0.10$ level. 


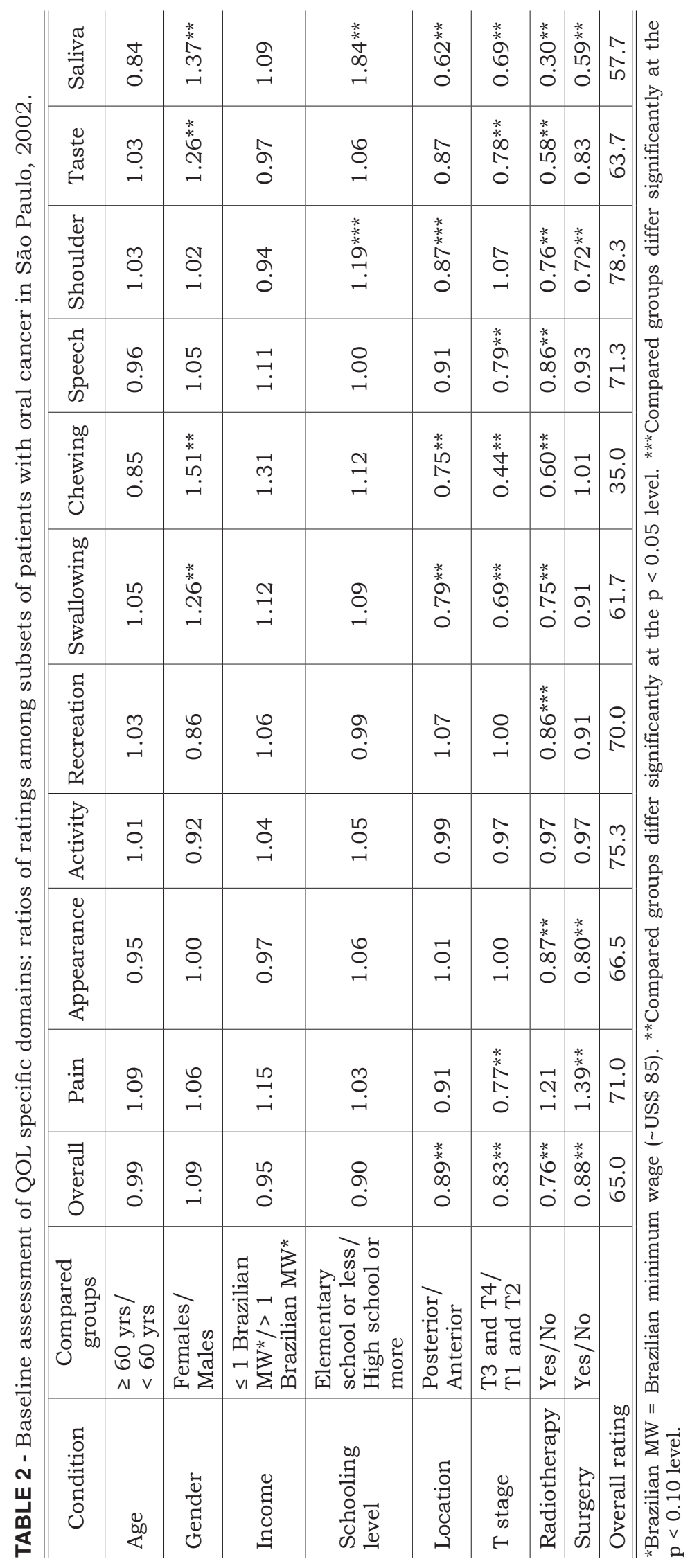


Andrade FP, Antunes JLF, Durazzo MD. Evaluation of the quality of life of patients with oral cancer in Brazil. Braz Oral Res 2006;20(4):290-6.

one-sided $\mathrm{p}$-value $=0.063)$, this difference was the only indication of a relative improvement in a QOL self-reported condition, as the remaining general and specific items of the questionnaire indicated equivalent results (Table 4). Chewing persisted as the lowest-rating specific item, and chewing, swallowing, saliva and pain remained as the most frequent complaints.

Table 4 also presents indications of concordance between answers and ratings taken at the

TABLE 3 - Baseline assessment of the most important complaints: ratios of proportions among subsets of patients with oral cancer in São Paulo, 2002.

\begin{tabular}{l|l|c|c|c|c}
\hline \multicolumn{1}{c|}{ Conditions } & \multicolumn{1}{|c|}{ Compared groups } & Chewing & Swallowing & Pain & Saliva \\
\hline Age & $\geq 60$ yrs/<60 yrs & 1.24 & 0.70 & 0.72 & $2.67^{* *}$ \\
\hline Gender & Females/Males & 0.76 & 0.55 & 0.93 & 0.63 \\
\hline Income & $\leq 1$ Brazilian $\mathrm{MW}^{*} />1$ Brazilian $\mathrm{MW}^{*}$ & 1.19 & 1.00 & 1.22 & 0.88 \\
\hline Schooling level & Elementary school or less/High school or more & 1.13 & 1.52 & 1.11 & $0.40^{* *}$ \\
\hline Location & Posterior/Anterior & 0.92 & 1.30 & 0.90 & 1.04 \\
\hline T stage & T3 and T4/T1 and T2 & $1.55^{* *}$ & $2.39^{* *}$ & 1.43 & 1.40 \\
\hline Radiotherapy & Yes/No & 1.13 & 0.78 & 0.59 & $22.5^{* *}$ \\
\hline Surgery & Yes/No & 0.96 & 1.00 & $0.45^{* *}$ & $1.88^{* * *}$ \\
\hline \multicolumn{1}{|c|}{ Overall proportion } & $50 \%$ & $33 \%$ & $29 \%$ & $24 \%$ \\
\hline \hline
\end{tabular}

${ }^{*}$ Brazilian MW $=$ Brazilian minimum wage ( US\$ 85). ${ }^{* *}$ Compared groups differ significantly at the p $<0.05$ level. ${ }^{* * *}$ Compared groups differ significantly at the $\mathrm{p}<0.10$ level.

TABLE 4 - Longitudinal assessment of answers to QOL general questions and ratings for specific domains for patients with oral cancer in São Paulo, 2002-3.

\begin{tabular}{l|c|c|c}
\hline \hline General questions & Baseline information & One-year follow-up & Overall agreement \\
\hline $\begin{array}{l}\text { Worse QOL compared to the month before } \\
\text { diagnosis }\end{array}$ & $50 \%$ (a) & $34 \%$ (b) & $59 \%$ \\
\hline $\begin{array}{l}\text { Poor health-related QOL during the preceding } \\
\text { week }\end{array}$ & $21 \%$ & $18 \%$ & $73 \%$ \\
\hline Poor overall QOL during the preceding week & $13 \%$ & $10 \%$ & $73 \%$ \\
\hline Ratings & Baseline information & One-year follow-up & Cronbach's alpha \\
\hline Overall & 65.8 & 67.1 & 0.877 \\
\hline Pain & 77.7 & 83.0 & 0.657 \\
\hline Appearance & 67.9 & 68.3 & 0.532 \\
\hline Activity & 75.9 & 70.5 & 0.319 \\
\hline Recreation & 71.4 & 67.4 & 0.303 \\
\hline Swallowing & 67.9 & 62.5 & 0.670 \\
\hline Chewing & 34.8 & 39.3 & 0.845 \\
\hline Speech & 73.8 & 74.4 & 0.569 \\
\hline Shoulder & 76.8 & 78.2 & 0.793 \\
\hline Taste & 59.5 & 67.3 & 0.309 \\
\hline Saliva & 52.4 & 60.3 & 0.621 \\
\hline Most important issues during the preceding week & Baseline information & One-year follow-up & Overall agreement \\
\hline Chewing & $50 \%$ & $54 \%$ & $73 \%$ \\
\hline Swallowing & $32 \%$ & $29 \%$ & $47 \%$ \\
\hline Saliva & $29 \%$ & $23 \%$ & $62 \%$ \\
\hline Pain & $21 \%$ & $14 \%$ & $36 \%$ \\
\hline \hline
\end{tabular}

$(a, b)$ Fisher's one-sided p-value $=0.063$. 
Andrade FP, Antunes JLF, Durazzo MD. Evaluation of the quality of life of patients with oral cancer in Brazil. Braz Oral Res 2006;20(4):290-6.

baseline and at the one-year follow-up. A high Cronbach's alpha for the overall ratings also indicated a reduced modification of QOL self reports informed by both surveys. Chewing was the most important issue during the preceding week, and the poorest rating domain in both assessments.

\section{DISCUSSION}

The assessment of QOL is a complex issue involving the overall and specific evaluation of different dimensions (speech, pain, chewing etc.) and covariates for socio-demographic and clinical conditions. As both the outcome and explaining variables entail multiple factors, alternative study designs could include multivariate assessments of QOL domains. However, we opted for a less complicated analytical scheme, and only estimated associations between unadjusted variables for the remaining factors modifying the QOL profile of patients.

The UW-QOL questionnaire has already been validated by studies comparing the results of its application with those obtained from other wellestablished questionnaires in the same field of study ${ }^{7}$. Besides comparing favourably in its ability to effectively assess QOL, the UW-QOL was appraised as a reliable, well-accepted (by respondents), practical and low-cost instrument for surveying the functional status of patients with head and neck cancer. However, the feasibility of its use in different languages still demands further research and its Portuguese version has not yet been formally validated.

The use of a Portuguese version of the UW-QOL questionnaire in the Brazilian context allowed the identification of different patterns of health-related QOL, which associated with socio-demographic and clinical characteristics of patients. Males and elder patients presented poorer ratings for some QOL specific domains. Patients with higher schooling level also appraised more critically some aspects of their own health status. Income did not associate with any QOL item; however, the cohort as a whole was comprised of low-income patients. The clinical status of patients was more predictive of self-reported QOL than socio-demographic characteristics. In general, participants with larger tumours and neoplasms in the posterior part of the mouth presented significantly poorer figures of QOL (Tables 1-3).

There is little surprise that patients would have reported worse QOL post-operatively than in the month preceding diagnosis. There is also little surprise that chewing was the lowest rated
QOL domain for patients who underwent major treatment for advanced oral and oropharyngeal cancer, and that patients treated with radiation complained of reduced saliva flow. As we collated baseline data of patients at different points in the course of treatment, a large number of patients $(57 / 100)$ had already been treated with surgery, and 40 of them had begun post-operative radiation therapy, when completing the questionnaire. The quantitative assessment of these contrasts was a specific target of the present field trial for the Portuguese version of the questionnaire.

We observed that patients treated with surgery and radiotherapy presented significantly worse QOL ratings and answers. This observation may be a manifestation of stage rather than treatment; the study design does not allow the conclusion that surgery plus radiation effectively causes worse QOL. Notwithstanding, this observation is consistent with that of several studies highlighting fluctuations of QOL levels depending on treatment type and phase. McDonough et al. ${ }^{4}$ (1996) used the UW-QOL for assessing QOL changes at various points throughout treatment, and observed a significant decrease of the overall ratings after surgery. Furthermore, they also observed surgery as associated with worse ranks in the scale used to assess avoidance of social interaction and anxiety in social situations. Rogers et al. ${ }^{6}$ (1998) identified a considerable deterioration of physical and social functioning three months after ablative surgery for oral cancer. However, they also observed that patients approached pretreatment scores by twelve months postoperatively.

Saliva and radiotherapy were the most discrepant pair of ratings for QOL specific domains (Table 2), and for proportions regarding the general question of major complaints during the week preceding the baseline assessment (Table 3). These observations are consistent with those of studies indicating radiotherapy as a cause for salivary dysfunction, xerostomia or reduced salivary flow. ${ }^{1,3}$

Notwithstanding the cross-sectional character of the study, and despite the fact that the original cross-section was not a representation of their original pre-treatment QOL status, we gathered information of patients at the one-year follow-up, in order to appraise overall changes in the long run. The comparison between baseline and followup information resulted in similar QOL patterns, indicating that patients tended to return to their former QOL ratings and answers. However, we registered slight indications of improved standards for 
Andrade FP, Antunes JLF, Durazzo MD. Evaluation of the quality of life of patients with oral cancer in Brazil. Braz Oral Res 2006;20(4):290-6.

surviving patients (Table 4), which can be due to decease or dropout of patients from the inception cohort. An overall enhancement of self-reported QOL status was also emphasised by studies assessing patients after one year of surgical treatment for oral cancer. ${ }^{6,8}$

Besides being the most prevalent complaint, and the lowest-rating QOL domain, difficulties in chewing presented relevant indications of persistence in the comparison of baseline and follow-up data. This observation accounts for the importance of the dental monitoring of patients in all phases of treatment and rehabilitation process, and suggests the importance of further studies assessing evolving trismus during and after radiation therapy, and possible ways to reconstruct and rehabilitate surgically treated patients. While performing a field trial of the questionnaire, it is important to acknowledge its ability to document the reduced QOL ratings for the chewing domain, both at the baseline and at the follow-up assessments, since one of the most important aspects of QOL research is to identify potential interventions while managing surgically treated patients.

\section{REFERENCES}

1. Epstein JB, Emerton S, Kolbinson DA, Le ND, Phillips N, Stenvenson-Moore P et al. Quality of life and oral function following radiotherapy for head and neck cancer. Head Neck. 1999;21(1):1-11.

2. Franceschi S, Bidoli S, Herrero R, Muñoz N. Comparison of cancers of the oral cavity and pharynx worldwide: etiological clues. Oral Oncol. 2000;36(1):106-15.

3. Henson BS, Inglehart MR, Eisbruch A, Ship JA. Preserved salivary output and xerostomia-related quality of life in head and neck cancer patients receiving parotid-sparing radiotherapy. Oral Oncol. 2001;37(1):84-93.

4. Mc Donough E, Varvares MA, Dunphy FR, Dunleavy T, Dunphy CH, Boyd JH. Changes in quality-of-life scores in a population of patients treated for squamous cell carcinoma of the head and neck. Head Neck. 1996;18(6):487-93.

5. Mirra AP, Latorre MRDO, Veneziano DB. Aspectos epidemiológicos do câncer no município de São Paulo: fatores de risco. Ministério da Saúde (INCA), Secretaria de Estado da Saúde (Oncocentro), Secretaria Municipal da Saúde (PRÓ-AIM). Faculdade de Saúde Pública: USP; 2003.

6. Rogers SN, Humphris G, Lowe D, Brown JS, Vaughan ED. The impact of surgery for oral cancer on quality of life as measured by the Medical Outcomes Short Form 36. Oral Oncol. 1998;34(3):171-9.

7. Rogers SN, Lowe D, Brown JS, Vaughan ED. A comparison between the University of Washington Head and Neck Disease-Specific measure and the Medical Short Form 36,

\section{CONCLUSION}

The present study appraised the UW-QOL as a feasible questionnaire for surveying the quality of life of patients with oral cancer in the Brazilian context. Besides being well accepted and easily answered by patients, the UW-QOL allowed identifying important contrasts and similarities among subsets of respondents. Chewing was identified as the poorest rating domain and presented the highest proportion of complaints in the sample of this study.

The adoption of a QOL assessment as a standard procedure in hospital settings can contribute to anticipate interventions aimed at reducing the impact of therapeutic applications and improve subsequent patient management.

\section{ACKNOWLEDGMENTS}

The present study was supported by a grant from the State of São Paulo Research Foundation (FAPESP, 02/02238-0), Brazil.

EORTC QOQ-C33 and EORTC Head and Neck 35. Oral Oncol. 1998;34(5):361-72.

8. Rogers SN, Lowe D, Brown JS, Vaughan ED. The University of Washington head and neck cancer measure as a predictor of outcome following primary surgery for oral cancer. Head Neck. 1999;21(5):394-401.

9. Stewart BW, Kleihues P, eds. World cancer report. Oxford: OUP, World Health Organization. International Agency for Research on Cancer: Oxford University Press; 2003.

10. Testa MA, Simonson DC. Assessment of quality-of-life outcomes. N Engl J Med. 1996;334(13):835-40.

11. The WHOQOL Group. The development of the World Health Organization quality of life assessment instrument (the WHOQOL). In: Orley J, Kuyken W, eds. Quality of life assessment: international perspectives. Heidelberg: Springer Verlag; 1994. p. 41-60.

12. The WHOQOL Group. The World Health Organization quality of life assessment (WHOQOL): development and general psychometric properties. Soc Sci Med. 1998;46(12):1569-85.

13. Weymuller Jr EA, Alsarraf R, Yueh B, Deleyiannis FW, Coltrera MD. Analysis of the performance characteristics of the University of Washington Quality of Life instrument and its modification. Arch Otolaryngol Head Neck Surg. 2001;127(5):489-93.

14. Wünsch-Filho V. The epidemiology of oral and pharynx cancer in Brazil. Oral Oncol. 2002;38(8):737-46. 